\title{
PHONETIC AND PHONOLOGICAL TRANSFER FROM NORTHERN VIETNAMESE TO ENGLISH IN CONSONANT CLUSTERS AND VOICELESS FINAL OBSTRUENTS
}

\author{
TRANSFERENCIA FONÉTICA Y FONOLÓGICA DEL \\ NORVIETNAMITA AL INGLÉS EN GRUPOS CONSONÁNTICOS \\ Y EN OCLUSIVAS SORDAS FINALES
}

José CARlos Pazos Riaño Universidad Nacional de Educación a Distancia (UNED)

jpazos32@alumno.uned.es

Fecha de recepción: 16-07-2021

Fecha de aceptación: 04-10-2021

\begin{abstract}
This article studies phonetic and phonological transfer from Northern Vietnamese to English observed in the production of consonant clusters and voiceless final obstruents. The pronunciation of a corpus of words in English produced by eight Northern Vietnamese participants has been obtained by means of two reading tasks and compared to the productions of two English speakers. The material has been auditorily and acoustically analysed following a descriptive approach and using a mixed methodology. The features that conform to phonetic and phonological transfer from Northern Vietnamese to English have been identified and analysed. Finally, some applications of this study have been proposed to help intelligibility in international contexts and to enhance the teaching of English to Northern Vietnamese students.
\end{abstract}

Key Words: Consonant cluster; International English; Northern Vietnamese; phonological transfer; RP English; voiceless final obstruent 


\section{RESUMEN}

Este trabajo estudia la trasferencia fonética y fonológica de los grupos consonánticos y de las consonantes oclusivas sordas en posición final de palabra desde el dialecto norvietnamita hacia el inglés. Se ha comparado la pronunciación de un corpus de palabras en inglés por ocho norvietnamitas con la pronunciación de dicho corpus por dos hablantes ingleses. El material utilizado en esta investigación ha sido analizado auditiva y acústicamente con un criterio descriptivo y mediante una metodología mixta. Se han identificado y estudiado los rasgos observados que se corresponden con trasferencias fonéticas y fonológicas. Por último, se han realizado propuestas para mejorar la inteligibilidad en contextos internacionales y para la enseñanza del inglés a estudiantes norvietnamitas.

PALABRAS ClAVE: consonante oclusiva sorda; dialecto norvietnamita; grupo consonántico; inglés internacional; transferencia fonológica; variedad RP del inglés

\section{INTRODUCTION}

This article aims to examine the pronunciation of English by Northern Vietnamese speakers and analyses the cases of phonetic and phonological interference from the subjects' L1 (Northern Vietnamese) to their L2 (English). In order to do that, we will compare the production of consonant clusters and voiceless final obstruents in the two languages. This study will also allow us to reconsider the concepts of correctness and English varieties.

The concept of correctness lacks a reference (correctness or incorrectness compared with what?). In the context of English as a Foreign Language, Received Pronunciation (RP) was considered as the standard, the 'teaching model for L2 learners of English and the point of reference against which their pronunciation should be judged' (JENKINS, 2000: 14). For many reasons, RP is no longer considered as the norm, and 'regional accents have now become the L1 rule and RP the exception' (JENKINS, 2000: 14-15). This fact is in line with the assertion that 'there is a single English language but many varieties' (SMITH, 1976: 38) because 'English belongs to the world and every nation which uses it does so with different tone, color, and quality' (SMITH, 1976: 39).

Accordingly, Northern Vietnamese English may be considered one more variety of English, such as Welsh English, South African English, or any other widely recognised variety worthy of being studied. Therefore, this research does not deal with the idea of correctness; it treats RP as a model, i.e., as a point of reference for the comparison of the Northern Vietnamese English variety, but not as a norm that must be followed.

We can distinguish three significant varieties of Vietnamese: Northern, Central and Southern Vietnamese. This article undertakes a study on the pronunciation of English by native speakers of the Northern Vietnamese community. In particular, it analyses some cases of phonetic or phonological transfer from L1 to L2 by Northern Vietnamese speakers, but not in terms of correctness, as explained above. 
Kachru (1992: 355-365) differentiated the world's users of English from a sociolinguistic point of view into three concentric circles: The 'Inner Circle' ${ }^{1}$ (normproviding), the 'Outer Circle" (norm-developing) and the 'Expanding Circle' ${ }^{3}$ (normdepending). However, this assumption about the restrictive three circles is highly questionable, at least from a linguistic perspective. According to his theory, Northern Vietnamese English belongs to the 'Expanding Circle', which is 'norm-depending'. Kachru develops his theory considering the English in his 'Inner Circle' as the norm, which is not the view of this research, which has been undertaken considering the Northern Vietnamese English as an established variety of English within the International English framework, worth being studied as such.

In a study carried out in a multilingual group of students, 'pronunciation emerged as by far the greatest factor in unintelligibility, and the difficulty tended to increase with the gap between interlocutors' first languages' (JENKINS, 2000: 19-20).

The problem of intelligibility is related to L2 inter-speaker variation, which 'involves the transfer of features of the particular L1 onto the production (and, of course, reception) of the target language' (JENKINS, 2000: 28). The purpose of this article is to study phonetic and phonological transfer from Northern Vietnamese to English. This topic is a very ample area to be studied here, which is the reason why this research article focuses on two characteristic features of Northern Vietnamese that differentiate it from English:

- Consonant clusters: Whereas English allows for consonant clusters with a maximum of three consonants in syllable onset position and up to four consonants in syllable coda position, Vietnamese syllables have no consonant clusters.

- Voiceless final obstruents: Only eight consonants can be found in the final position of the Vietnamese syllables, as opposed to 20 consonants that are recognised in that position in English. Furthermore, when the voiceless obstruents (/p t k/) are in the final position of Vietnamese syllables, they are always unreleased, whereas these consonants in the same position can be released in English.

All the different dialects of the Vietnamese language spoken by native speakers in Vietnam can be grouped into three main dialects. As Alves (2009: 1) indicates, 'Vietnamese is considered to have three general regional varieties - Northern, Central, and Southern Vietnamese- which are represented by the speech of the cities of Hanoi (northern), Hue (central), and Ho Chi Minh City (southern) respectively'. However, one characteristic of all Vietnamese dialects is that they do not have consonant clusters or blends: 'Consonant blends occur in all word positions (i.e., initial, medial, and final) in English, whereas there are no consonant blends in Vietnamese' (CHENG, 1987: 41).

\footnotetext{
1 'The Inner Circle refers to the traditional cultural and linguistic bases of English', i.e. the native varieties of English.

2 'The Outer Circle represents the institutionalized non-native varieties (ESL) in the regions that have been passed through extended periods of colonization'.

3 'The Expanding Circle includes the regions where the performance varieties of the language are used essentially in EFL contexts'.
} 
Although De Rhodes's (1651) Vietnamese-Portuguese-Latin dictionary included some consonant clusters, as /bl-/, /ml-/, /mnh-/ and /tl-/ (DE RHODES, 1651), "no dialect in Modern Vietnamese has retained any of those consonant clusters, which had existed -as sounds- at least up to the seventeenth century' (NGUYẼN, 1997: 21).

In Northern Vietnamese, there exists the orthographic group $t r$, which is pronounced (similarly as the group $c h$ ) as the affricate / $\mathrm{t} 6 /$ and not as the consonant cluster /tr/. As Kirby (2011: 382) observes, '[in] the speech of many younger Vietnamese native speakers from Hanoi $[\ldots]$ this segment is consistently realized as an affricate [t6]'. The palatal affricate $/ \mathrm{t} 6 /$ has been observed in the pronunciation and testimony of all the participants in this study.

Northern Vietnamese phonology includes eight final phonemes: 'Hanoi Vietnamese licenses eight segments in coda position: three unreleased voiceless obstruents $/ \mathrm{p} \mathrm{t} \mathrm{k/} \mathrm{[p}$ $\overrightarrow{\mathrm{t}} \mathrm{k}]$, three nasals /m n $\mathrm{y} /$, and two approximants /j w/' (KIRBY, 2011: 383). One crucial difference between Vietnamese and English regarding consonants in coda position is that "in Vietnamese, syllable-final /p, t, k/ are unreleased or "held in", whereas these sounds may be released in English' (TANG, 2007: 6).

In a bilingual context, like the one in which this research work was developed ${ }^{4}$, interspeaker variation is prevalent; this variation involves a process of transfer of features from the source language (L1) to the target language (L2). The most noticeable aspects of this transfer are phonetic and phonological.

Two phenomena can occur between the sounds of two languages (L1 and L2): either they are very different or share some similarities.

Sounds that are phonetically very different from those in the L1 are initially likely to prove most difficult to produce, since the articulators must be activated in new ways. On the other hand, where there is any degree of similarity between L1 and L2 sounds, there is a tendency to identify the two, and thence to categorise the new sounds in terms of the old (JENKINS, 2000: 33).

This quotation alludes to negative and positive transfer (very different sounds and similar sounds, respectively), which is related to the concepts of intelligibility and correctness; however, these issues are out of the scope of this research. Likewise, although Jenkins refers to the phonetic aspect (sounds), we also apply her statement to phonological transfer.

Consonant cluster is a feature absent in the Northern Vietnamese phonological system, and the three final obstruents in Northern Vietnamese (/p/, /t/ and $/ \mathrm{k} /)$ also exist in English, but they are produced as unreleased in the former and can be released in English. Consonant clusters are difficult to produce by Northern Vietnamese speakers because they are absent in their language; therefore, they must be included in the first case mentioned by Jenkins, namely 'sounds that are phonetically very different'. On the other hand, the three

\footnotetext{
4 The Northern Vietnamese participants were either teachers of English or employees in international companies, where they used to work in English.
} 
Northern Vietnamese final obstruents may be identified by L1 speakers as similar to the English voiceless final obstruents, which illustrates the second case mentioned by Jenkins, namely 'where there is any degree of similarity'.

The hypothesis that this article will try to prove is that both phenomena (differences and similarities between the two phonetic and phonological systems) may activate transfer from L1 to L2, i.e., from Northern Vietnamese to English. So that not only the differences but also the similarities of both phonological or phonetic systems, may trigger phonological or phonetic transfer, respectively. In the case of consonant clusters, the transfer studied is phonological since we will compare the phonological systems of both languages. When dealing with the voiceless final obstruents, the transfer can be either phonetic, if we compare the realisations of these phonemes, or phonological, if we observe cases of substitution or deletion of phonemes. This article will show that the transfer observed from L1 to L2 is related to the differences in the phonological and phonetic systems of both languages.

\section{METHOD}

\subsection{Experimental Procedure}

The methodology used in this research can be classified as a mixed methodology, somewhere in between the QUAL-QUAN extremes because features of both methodologies have been taken into account. This work starts following a quantitative methodology because it collects and analyses data showing the number of occurrences of particular phonemes and their realisations among a group of Northern Vietnamese speakers. Furthermore, it also includes a qualitative analysis of the data, which was undertaken by observing the acoustic representations and auditory perceptions of the target productions.

This research is not prescriptive, and the participants were informed of that. As the introduction of this article explains, we did not consider RP as the norm but as a model, the variety of English with which Northern Vietnamese was compared; therefore, we avoided the idea of correctness and worked under a descriptive perspective.

The participants read the texts of the corpus while they were recorded, and the audio files obtained are the primary material for this research. The audio files were analysed with the software Praat (BOERSMA and WEENINK, 2005), observing the phonemes, and allophones in some cases, produced by the participants regarding each of the features studied (consonant clusters and voiceless final obstruents).

\subsection{Corpus}

The corpus of this research was obtained from two different sources: a literary text and a list of words. Usually, the participants read more naturally a text than isolated words; that is because, while reading a text, they fix their attention on the content rather than on the 
form of the words. For this reason, when the same word appears in the text and the list of words, we preferred to analyse it from the list to avoid the mechanisms of connected speech that may interfere in the study.

The text selected is the beginning of the novel Pride and Prejudice by Jane Austen. These paragraphs contain no problematic vocabulary for speakers with a high level of English — as is the case of the participants - and words with a variety of phonemic features which are relevant for this study (consonant clusters and voiceless final obstruents). Likewise, the words in the list contain an increasing number of those features. Participants usually read isolated words in a list more carefully and focus their attention on their pronunciation. Furthermore, the words in the text were pronounced in connected speech and the words in the list in isolation.

The corpus includes target words and distractors to divert the attention of the participants from the objective of this research. The following lists include the target words classified according to the phonemes studied:

- Consonant clusters: This research studies the following consonant clusters classified according to their position in the word (onset, medial and coda), and the words studied are listed after the phonemic transcription of the corresponding consonant cluster:
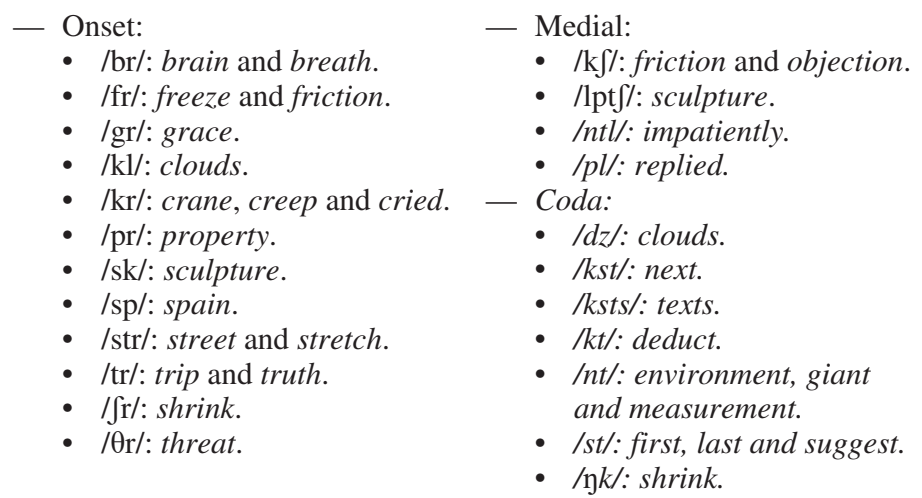

- Voiceless Final Obstruents: The three final obstruents in the Northern Vietnamese phonemic repertoire are $/ \mathrm{p} /, \mathrm{t} / \mathrm{and} / \mathrm{k} /$. The words analysed in this study are:

- /p/: backup, cheap, creep, gap, soup, top and trip.

- /t/: bennet, coat, it, street and threat.

- /k/: park and take.

\subsection{Participants}

The participants in this research were eight Northern Vietnamese native speakers and two English native speakers. They — six women and four men— were between 30 and 50 years old. 
The two English participants, teachers of English with high education levels, came from towns around Cambridge, and their productions were considered as RP English in this research, which was used as models, as explained in previous sections.

The eight Vietnamese participants had a high education level, but not specifically in linguistics; they were natives from areas less than $100 \mathrm{~km}$ away from Hanoi, so their pronunciation was considered Northern Vietnamese. They had a proficient level of English, which they used daily in their work in international companies. All these participants were informed that they would be recorded to undertake a study of their pronunciation and that, after this study, we could get to conclusions about how the Vietnamese phonemic system could influence the pronunciation of their speech in English. This general information was necessary to get consent for their participation and convenient to encourage them to read with their best pronunciation. The ethical aspect of the research was fulfilled because the participants were sincerely informed of its general purpose, and their anonymity was preserved. However, the participants were not informed of the specific goal of this study (consonant clusters and voiceless final obstruents), so they could not alter their productions. The experiment can be considered blind to these participants, who had not enough linguistic knowledge to guess the concrete objectives of this research.

\subsection{Data Recording and Analysis}

The participants were given the text and the list of words that were the source of the corpus and were explained the general purpose of this research. They were recorded in a silent room with a digital voice recorder (Olympus LS-P4) while reading. Two audio files (*.wav) per participant were obtained, one for the text and the other for the list of isolated words.

With the help of the software Praat (BOERSMA and WEENINK, 2005), forty audio files were extracted per participant corresponding to the production of the target words. Overall, four hundred audio files have been analysed in this research.

Two types of analysis were undertaken: acoustic with the software Praat and auditory. The analysis identified the phonemes produced for every one of the features studied: twenty-three consonant clusters and three voiceless final obstruents. In some cases, the auditory observation was corroborated by the acoustic study of the waveforms, spectrograms, and formants to identify the phonemes produced and how these phonemes were realised (phonological and phonetic information), and it was supported by the reporting and clarifications of the participants. 


\section{RESULTS}

\subsection{Results of the Auditory Analysis}

\subsubsection{Consonant Clusters}

Table 1 shows the phonemic transcription in IPA signs of the production of each consonant cluster by each participant (the study of the productions of the consonant clusters was undertaken at the phonological level). The second column of this table shows the phonological transcription of the corresponding consonant cluster in RP, classified according to their position in the word (onset, medial or coda).

The last three columns are the quantification of the data obtained. The first of these last columns includes the number of occurrences of the RP phonemes in the production of each consonant cluster. The following column contains the percentage of occurrences of the RP phonemes over the total number of productions of that consonant cluster in the corresponding word (eight, one per participant); and the last column shows the percentage of occurrences of the RP phonemes over the total number of productions of the corresponding consonant cluster, taking into account that some consonant clusters are present in more than one word.

Table 1: Production of consonant clusters.

\begin{tabular}{|c|c|c|c|c|c|c|c|c|c|c|c|c|c|}
\hline \multirow{2}{*}{\multicolumn{2}{|c|}{$\begin{array}{c}\text { Consonan } \\
\text { Clusters } \\
\text { (CC) }\end{array}$}} & \multirow{2}{*}{$\begin{array}{c}\text { Words } \\
\text { (W) }\end{array}$} & \multicolumn{8}{|c|}{ Participants } & \multicolumn{3}{|c|}{ RP Occurrences } \\
\hline & & & 1 & 2 & 3 & 4 & 5 & 6 & 7 & 8 & n. & $\%$ in $\mathrm{W}$ & $\%$ in $\mathrm{CC}$ \\
\hline & \multirow{2}{*}{ /br/ } & brain & /br/ & $/ \operatorname{tr} /$ & /br/ & /br/ & /br/ & $/ \mathrm{pr} /$ & /br/ & /br/ & 6 & $75 \%$ & \multirow{2}{*}{$75 \%$} \\
\hline & & breath & /br/ & /bar/ & $/ \mathrm{br} /$ & /br/ & /br/ & /br/ & /bər/ & /br/ & 6 & $75 \%$ & \\
\hline & \multirow{2}{*}{ /fr/ } & freeze & $/ \mathrm{pr} /$ & $/ \mathrm{fr} /$ & $/ \mathrm{fr} /$ & $/ \mathrm{fr} /$ & $/ \mathrm{tr} /$ & $/ \mathrm{fr} /$ & $/ \mathrm{fr} /$ & $/ \mathrm{fr} /$ & 6 & $75 \%$ & \multirow{2}{*}{$75 \%$} \\
\hline & & friction & $/ \mathrm{fr} /$ & $/ \mathrm{fr} /$ & $/ \mathrm{fr} /$ & $/ \mathrm{fr} /$ & $/ \mathrm{br} /$ & $/ \mathrm{pr} /$ & $/ \mathrm{fr} /$ & $/ \mathrm{fr} /$ & 6 & $75 \%$ & \\
\hline \multirow{14}{*}{ 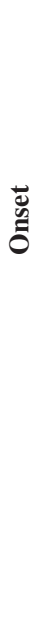 } & /gr/ & grace & $/ \mathrm{kr} /$ & /gr/ & /gr/ & /br/ & /br/ & $/ \mathrm{br} /$ & /br/ & /gr/ & 3 & $38 \%$ & $38 \%$ \\
\hline & $/ \mathrm{kl} /$ & clouds & $/ \mathrm{kl} /$ & $/ \mathrm{kl} /$ & $/ \mathrm{kl} /$ & $/ \mathrm{kl} /$ & $/ \mathrm{kl} /$ & $/ \mathrm{kl} /$ & $/ \mathrm{kl} /$ & $/ \mathrm{kl} /$ & 8 & $100 \%$ & $100 \%$ \\
\hline & \multirow{3}{*}{$/ \mathrm{kr} /$} & crane & $/ \mathrm{kr} /$ & $/ \mathrm{kr} /$ & /br/ & $/ \mathrm{kr} /$ & $/ \mathrm{kr} /$ & $/ \mathrm{kr} /$ & $/ \mathrm{kr} /$ & $/ \mathrm{kr} /$ & 7 & $88 \%$ & \multirow{3}{*}{$88 \%$} \\
\hline & & creep & $/ \mathrm{kr} /$ & $/ \mathrm{kr} /$ & $/ \mathrm{kr} /$ & $/ \mathrm{kr} /$ & $/ \mathrm{kr} /$ & $/ \mathrm{kr} /$ & $/ \mathrm{kr} /$ & $/ \mathrm{kr} /$ & 8 & $100 \%$ & \\
\hline & & cried & $/ \mathrm{kr} /$ & $/ \mathrm{kr} /$ & /gr/ & $/ \mathrm{kr} /$ & $/ \mathrm{kr} /$ & /br/ & $/ \mathrm{kr} /$ & $/ \mathrm{kr} /$ & 6 & $75 \%$ & \\
\hline & $/ \mathrm{pr} /$ & property & $/ \mathrm{pr} /$ & $/ \mathrm{pr} /$ & $/ \mathrm{pr} /$ & $/ \mathrm{pr} /$ & $/ \mathrm{pr} /$ & $/ \mathrm{pr} /$ & $/ \mathrm{pr} /$ & $/ \mathrm{p} /$ & 7 & $88 \%$ & $88 \%$ \\
\hline & /sk/ & sculpture & /sk/ & /sk/ & $/ \mathrm{sk} /$ & $/ \mathrm{sk} /$ & /sk/ & /sk/ & $/ \mathrm{sk} /$ & /sk/ & 8 & $100 \%$ & $100 \%$ \\
\hline & /sp/ & spain & $/ \mathrm{sp} /$ & $/ \mathrm{sp} /$ & $/ \mathrm{sp} /$ & $/ \mathrm{sp} /$ & $/ \mathrm{sp} /$ & $/ \mathrm{sp} /$ & $/ \mathrm{sp} /$ & $/ \mathrm{sp} /$ & 8 & $100 \%$ & $100 \%$ \\
\hline & \multirow{2}{*}{ /str/ } & street & /ste/ & /str/ & $/ \mathrm{sr} /$ & $/$ str/ & $/ \mathrm{str} /$ & /str/ & $/ \mathrm{str} /$ & $/ \mathrm{sr} /$ & 5 & $63 \%$ & \multirow{2}{*}{$69 \%$} \\
\hline & & stretch & /oste/ & /str/ & /str/ & /str/ & $/ \mathrm{str} /$ & /str/ & /str/ & $/ \mathrm{sr} /$ & 6 & $75 \%$ & \\
\hline & \multirow{2}{*}{$/ \mathrm{tr} /$} & trip & $/ \mathrm{tc} /$ & $/ \mathrm{tr} /$ & $/ \mathrm{tr} /$ & $/ \mathrm{t} 6 /$ & $/ \mathrm{tr} /$ & $/ \mathrm{tr} /$ & $/ \mathrm{tc} /$ & $/ \mathrm{tr} /$ & 5 & $63 \%$ & \multirow{2}{*}{$63 \%$} \\
\hline & & truth & $/ \mathrm{tc} /$ & $/ \mathrm{tr} /$ & $/ \mathrm{t} 6 /$ & $/ \mathrm{t} 6 /$ & $/ \mathrm{tr} /$ & $/ \mathrm{tr} /$ & $/ \mathrm{tr} /$ & $/ \mathrm{tr} /$ & 5 & $63 \%$ & \\
\hline & $/ \int \mathrm{r} /$ & shrink & /swo/ & $/ \mathrm{sr} /$ & $/ \int \mathrm{w} /$ & $/ \int \mathrm{r} /$ & $/ \mathrm{sr} /$ & $/ \mathrm{sr} /$ & $/ \mathrm{sr} /$ & /str/ & 1 & $13 \%$ & $13 \%$ \\
\hline & $/ \theta \mathrm{r} /$ & threat & $/ \mathrm{tr} /$ & $/ \theta \mathrm{r} /$ & $/ \mathrm{tr} /$ & $/ \mathrm{tr} /$ & $/ \mathrm{tr} /$ & $/ \mathrm{tr} /$ & $/ \mathrm{tr} /$ & $/ \theta \mathrm{r} /$ & 2 & $25 \%$ & $25 \%$ \\
\hline
\end{tabular}




\begin{tabular}{|c|c|c|c|c|c|c|c|c|c|c|c|c|c|}
\hline \multirow{2}{*}{\multicolumn{2}{|c|}{$\begin{array}{l}\text { Consonant } \\
\text { Clusters } \\
\text { (CC) }\end{array}$}} & \multirow{2}{*}{$\begin{array}{c}\text { Words } \\
\text { (W) }\end{array}$} & \multicolumn{8}{|c|}{ Participants } & \multicolumn{3}{|c|}{ RP Occurrences } \\
\hline & & & 1 & 2 & 3 & 4 & 5 & 6 & 7 & 8 & n. & $\%$ in $\mathrm{W}$ & $\%$ in $\mathrm{CC}$ \\
\hline \multirow{5}{*}{ : } & \multirow{2}{*}{$/ \mathrm{kg} /$} & friction & $/ \mathrm{s} /$ & $/ \mathrm{ks} /$ & $/ \mathrm{ks} /$ & $/ \mathrm{kgl}$ & $/ \mathrm{kJl}$ & $/ \mathrm{kgl}$ & $/ \mathrm{k} f /$ & $/ \mathrm{kgl}$ & 5 & $63 \%$ & \multirow{2}{*}{$69 \%$} \\
\hline & & objection & lg/ & $/ \mathrm{k} f /$ & $/ \mathrm{d} /$ & $/ \mathrm{k} \int /$ & $/ \mathrm{kJl}$ & $/ \mathrm{kgl}$ & $/ \mathrm{kg} /$ & $/ \mathrm{kgl}$ & 6 & $75 \%$ & \\
\hline & $/ \mathrm{lpt} \int /$ & sculpture & $/ \mathrm{tc} /$ & $/ \mathrm{tc} /$ & /pte/ & $/ \mathrm{mtg} /$ & $/ \mathrm{mp} /$ & $/ \mathrm{lp} /$ & $/ 1 /$ & $/ \mathrm{ptc} /$ & 0 & $0 \%$ & $0 \%$ \\
\hline & $/ \mathrm{ntl} /$ & impatiently & $/ \mathrm{nl} /$ & $/ \mathrm{ntl} /$ & $/ \mathrm{nl} /$ & $/ \mathrm{ntl} /$ & $/ \mathrm{ntl} /$ & $/ \mathrm{nl} /$ & $/ \mathrm{tc} 1 /$ & $/ \mathrm{nl} /$ & 3 & $38 \%$ & $38 \%$ \\
\hline & $/ \mathrm{pl} /$ & replied & $/ \mathrm{pl} /$ & $/ \mathrm{pl} /$ & $/ \mathrm{pl} /$ & $/ \mathrm{pl} /$ & $/ \mathrm{pl} /$ & $/ \mathrm{pl} /$ & /f1/ & $/ \mathrm{pl} /$ & 7 & $88 \%$ & $88 \%$ \\
\hline \multirow{11}{*}{ نَّ } & $/ \mathrm{dz} /$ & clouds & $|z|$ & $/ \mathrm{dz} /$ & $/ \mathrm{d} /$ & $|z|$ & $/ \mathrm{dz} /$ & $|z|$ & $/ \mathrm{d} /$ & $/ \mathrm{d} /$ & 2 & $25 \%$ & $25 \%$ \\
\hline & $/ \mathrm{kst} /$ & next & $/ \mathrm{s} /$ & /st/ & /kst/ & /kst/ & $/ \mathrm{kst} /$ & $/ \mathrm{kst} /$ & $/ \mathrm{k} /$ & $/ \mathrm{t} /$ & 4 & $50 \%$ & $50 \%$ \\
\hline & /ksts/ & texts & /st/ & /kst/ & /kst/ & /kst/ & /kst/ & /st/ & $/ \mathrm{ks} /$ & $/ \mathrm{k} /$ & 0 & $0 \%$ & $0 \%$ \\
\hline & $/ \mathrm{kt} /$ & deduct & $/ \mathrm{kt} /$ & $/ \mathrm{kt} /$ & $/ \mathrm{kt} /$ & $/ \mathrm{kt} /$ & $/ \mathrm{k} /$ & I-I & $/ \mathrm{x} /$ & $/ \mathrm{kt} /$ & 5 & $63 \%$ & $63 \%$ \\
\hline & \multirow{3}{*}{$/ \mathrm{nt} /$} & environment & $/ \mathrm{n} /$ & $/ \mathrm{nt} /$ & $/ \mathrm{n} /$ & /nt/ & $/ \mathrm{nt} /$ & $/ \mathrm{n} /$ & $/ \mathrm{n} /$ & $/ \mathrm{nt} /$ & 4 & $50 \%$ & \multirow{3}{*}{$63 \%$} \\
\hline & & giant & /st/ & $/ \mathrm{nt} /$ & $/ \mathrm{n} /$ & $/ \mathrm{nt} /$ & /nt/ & $/ \mathrm{n} /$ & $/ \mathrm{n} /$ & $/ \mathrm{nt} /$ & 4 & $50 \%$ & \\
\hline & & measurement & $/ \mathrm{nt} /$ & $/ \mathrm{nt} /$ & $/ \mathrm{nt} /$ & $/ \mathrm{nt} /$ & $/ \mathrm{nt} /$ & $/ \mathrm{nt} /$ & I-I & $/ \mathrm{nt} /$ & 7 & $88 \%$ & \\
\hline & \multirow{3}{*}{ /st/ } & first & $/ \mathrm{k} /$ & /st/ & /st/ & /st/ & /st/ & $/ \mathrm{k} /$ & /st/ & /st/ & 6 & $75 \%$ & \multirow{3}{*}{$71 \%$} \\
\hline & & last & /st/ & /st/ & /st/ & /st/ & /st/ & /st/ & /st/ & /st/ & 8 & $100 \%$ & \\
\hline & & suggest & $/ \mathrm{s} /$ & /st/ & $/ \mathrm{s} /$ & /st/ & /st/ & $/ \mathrm{t}_{\mathrm{c}} /$ & $/ \mathrm{s} /$ & $/ \mathrm{t} /$ & 3 & $38 \%$ & \\
\hline & $/ \mathrm{nk} /$ & shrink & $/ \mathrm{y} /$ & $/ \mathrm{nk} /$ & $/ \mathrm{nk} /$ & $/ \mathrm{nk} /$ & $/ \mathrm{nk} /$ & $/ \mathrm{y} /$ & $/ \mathrm{nk} /$ & $/ \mathrm{nk} /$ & 6 & $75 \%$ & $75 \%$ \\
\hline
\end{tabular}

\subsubsection{Voiceless Final Obstruents}

Table 2 shows the pronunciation of the final obstruent $/ \mathrm{p} /$ in seven target words. The symbols '[+]' or '[-]' have been added after/p/ depending on whether the production was released or unreleased, respectively.

Table 2. Production of final /p/ ('[+]' released or '[-]' unreleased).

\begin{tabular}{|c|c|c|c|c|c|c|c|c|}
\hline \multirow{2}{*}{ Words } & \multicolumn{9}{|c|}{ Participants } \\
\cline { 2 - 9 } & $\mathbf{1}$ & $\mathbf{2}$ & $\mathbf{3}$ & $\mathbf{4}$ & $\mathbf{5}$ & $\mathbf{6}$ & $\mathbf{7}$ & $\mathbf{8}$ \\
\hline backup & $/ \mathrm{p} /[-]$ & $/ \mathrm{p} /[+]$ & $/ \mathrm{p} /[+]$ & $/ \mathrm{p} /[+]$ & $/ \mathrm{p} /[+]$ & $/ \mathrm{p} /[-]$ & $/ \mathrm{p} /[+]$ & $/ \mathrm{p} /[-]$ \\
\hline cheap & $/ \mathrm{p} /[+]$ & $/ \mathrm{p} /[+]$ & $/ \mathrm{p} /[+]$ & $/ \mathrm{p} /[+]$ & $/ \mathrm{p} /[+]$ & $/ \mathrm{p} /[-]$ & $/ \mathrm{p} /[+]$ & $/ \mathrm{p} /[-]$ \\
\hline creep & $/ \mathrm{p} /[+]$ & $/ \mathrm{p} /[+]$ & $/ \mathrm{p} /[+]$ & $/ \mathrm{p} /[+]$ & $/ \mathrm{p} /[+]$ & $/ \mathrm{p} /[+]$ & $/ \mathrm{p} /[+]$ & $/ \mathrm{p} /[+]$ \\
\hline gap & $/ \mathrm{p} /[+]$ & $/ \mathrm{p} /[+]$ & $/ \mathrm{p} /[+]$ & $/ \mathrm{p} /[+]$ & $/ \mathrm{p} /[+]$ & $/ \mathrm{p} /[-]$ & $/ \mathrm{p} /[+]$ & $/ \mathrm{p} /[-]$ \\
\hline soup & $/ \mathrm{p} /[+]$ & $/ \mathrm{p} /[+]$ & $/ \mathrm{p} /[+]$ & $/ \mathrm{p} /[+]$ & $/ \mathrm{p} /[-]$ & $/ \mathrm{p} /[+]$ & $/ \mathrm{p} /[+]$ & $/ \mathrm{p} /[+]$ \\
\hline top & $/ \mathrm{p} /[-]$ & $/ \mathrm{p} /[+]$ & $/ \mathrm{p} /[+]$ & $/ \mathrm{p} /[-]$ & $/ \mathrm{p} /[+]$ & $/ \mathrm{p} /[-]$ & $/ \mathrm{p} /[+]$ & $/ \mathrm{p} /[-]$ \\
\hline trip & $/ \mathrm{p} /[+]$ & $/ \mathrm{p} /[+]$ & $/ \mathrm{p} /[+]$ & $/ \mathrm{p} /[+]$ & $/ \mathrm{p} /[+]$ & $/ \mathrm{p} /[-]$ & $/ \mathrm{p} /[+]$ & $/ \mathrm{p} /[+]$ \\
\hline
\end{tabular}

The results included in Table 2 have been quantified in Table 3, where columns 2, 3 and 4 include, for each word, the number of occurrences of the following productions: 
- The corresponding phoneme in RP (/p/).

- The corresponding phoneme and mechanism $(/ \mathrm{p} /$ released $=$ ' $/ \mathrm{p} /[+] ')$.

- Other phonemes that are different from $/ \mathrm{p} /$.

Columns 5, 6 and 7 include the percentages of the previous occurrences over the number of productions of each word (eight, one per participant). The last three columns contain the percentages of the occurrences over the total number of productions of this final obstruent ( 7 words $\mathrm{x} 8$ participants $=56$ productions).

Table 3. Quantification of the production of final /p/ ('[+]' released or '[-]' unreleased).

\begin{tabular}{|c|c|c|c|c|c|c|c|c|c|}
\hline \multirow[t]{2}{*}{ Words } & \multirow[t]{2}{*}{$/ \mathrm{p} /$} & \multirow[t]{2}{*}{$/ \mathrm{p} /[+]$} & \multirow[t]{2}{*}{ other } & \multicolumn{3}{|c|}{$\%$ over words } & \multicolumn{3}{|c|}{$\%$ over FO } \\
\hline & & & & $/ \mathrm{p} /$ & $/ \mathbf{p} /[+]$ & other & $/ \mathrm{p} /$ & $/ p /[+]$ & other \\
\hline backup & 8 & 5 & 0 & $100 \%$ & $63 \%$ & $0 \%$ & \multirow{7}{*}{$100 \%$} & \multirow{7}{*}{$77 \%$} & \multirow{7}{*}{$0 \%$} \\
\hline cheap & 8 & 6 & 0 & $100 \%$ & $75 \%$ & $0 \%$ & & & \\
\hline creep & 8 & 8 & 0 & $100 \%$ & $100 \%$ & $0 \%$ & & & \\
\hline gap & 8 & 6 & 0 & $100 \%$ & $75 \%$ & $0 \%$ & & & \\
\hline soup & 8 & 7 & 0 & $100 \%$ & $88 \%$ & $0 \%$ & & & \\
\hline top & 8 & 4 & 0 & $100 \%$ & $50 \%$ & $0 \%$ & & & \\
\hline trip & 8 & 7 & 0 & $100 \%$ & $88 \%$ & $0 \%$ & & & \\
\hline
\end{tabular}

According to these results, $77 \%$ of the times the participants pronounced a released final /p/, i.e. following the RP model, and $23 \%$ of the times the final /p/ was unreleased. In this latter case, there is a phonetic transfer from Northern Vietnamese to English. We can infer, from the results obtained, that Northern Vietnamese speakers of English always pronounce the final $/ \mathrm{p} /$, and more than three-fourths of the times this pronunciation is released, so mostly they can adapt it to the RP pronunciation.

Table 4 includes the pronunciation observed of the final obstruent $/ \mathrm{t} / \mathrm{in}$ the target words. Table 5 includes the corresponding quantifications of these results. The contents in the columns of Table 5 follow the same criteria as explained for Table 3.

Table 4: Production of final /t/ ('[+]' released or '[-]' unreleased).

\begin{tabular}{|l|c|c|c|c|c|c|c|c|}
\hline \multirow{3}{*}{ Words } & \multicolumn{7}{|c|}{ Participants } \\
\cline { 2 - 9 } & $\mathbf{1}$ & $\mathbf{2}$ & $\mathbf{3}$ & $\mathbf{4}$ & $\mathbf{5}$ & $\mathbf{6}$ & $\mathbf{7}$ & $\mathbf{8}$ \\
\hline bennet & $/ \mathrm{t} 6 /$ & $/ \mathrm{t} 6 /$ & $/ \theta /$ & $/ \mathrm{t} /[-]$ & $/ \mathrm{t} /[-]$ & $/ \theta /$ & $/ \mathrm{t} /[-]$ & $/ \mathrm{t} /[+]$ \\
\hline coat & $/ \mathrm{st} /[-]$ & $/ \mathrm{t} /[+]$ & $/ \mathrm{t} /[+]$ & $/ \mathrm{t} /[+]$ & $/ \mathrm{t} /[+]$ & $/ \mathrm{t} /[-]$ & $/ \mathrm{t} /[+]$ & $/ \mathrm{t} /[+]$ \\
\hline it & $/ \mathrm{t} /[-]$ & $/ \mathrm{t} 6 /$ & $/ \mathrm{t} /[-]$ & $/ \mathrm{t} /[-]$ & $/ \mathrm{t} /[+]$ & $/ \mathrm{t} /[-]$ & $/ \mathrm{z} /$ & $/ \mathrm{t} /[+]$ \\
\hline street & $/ \mathrm{z} /$ & $/ \mathrm{t} /[+]$ & $/ \mathrm{t} /[-]$ & $/ \mathrm{t} /[+]$ & $/ \mathrm{t} /[+]$ & $/ \mathrm{t} /[+]$ & $/ \theta /$ & $/ \mathrm{t} /[+]$ \\
\hline
\end{tabular}




\begin{tabular}{|l|c|c|c|c|c|c|c|c|}
\hline \multirow{3}{*}{ Words } & \multicolumn{10}{|c|}{ Participants } \\
\cline { 2 - 9 } & $\mathbf{1}$ & $\mathbf{2}$ & $\mathbf{3}$ & $\mathbf{4}$ & $\mathbf{5}$ & $\mathbf{6}$ & $\mathbf{7}$ & $\mathbf{8}$ \\
\hline threat & $/ \mathrm{z} /$ & $/ \mathrm{t} /[+]$ & $/ \mathrm{t} /[+]$ & $/ \mathrm{t} /[-]$ & $/ \mathrm{ts} /$ & $/ \mathrm{z} /$ & $/ \mathrm{z} /$ & $/ \mathrm{t} /[+]$ \\
\hline
\end{tabular}

Table 5: Quantification of the production of final /t/ ('[+]' released or '[-]' unreleased).

\begin{tabular}{|c|c|c|c|c|c|c|c|c|c|}
\hline \multirow[t]{2}{*}{ Words } & \multirow[t]{2}{*}{$/ \mathrm{t} /$} & \multirow[t]{2}{*}{$/ \mathrm{t} /[+]$} & \multirow[t]{2}{*}{ other } & \multicolumn{3}{|c|}{$\%$ over words } & \multicolumn{3}{|c|}{$\%$ over FO } \\
\hline & & & & $/ \mathrm{t} /$ & $/ t /[+]$ & other & $/ t /$ & $/ t /[+]$ & other \\
\hline bennet & 4 & 1 & 4 & $50 \%$ & $13 \%$ & $50 \%$ & \multirow{5}{*}{$67 \%$} & \multirow{5}{*}{$42 \%$} & \multirow{5}{*}{$33 \%$} \\
\hline coat & 7 & 6 & 1 & $88 \%$ & $75 \%$ & $13 \%$ & & & \\
\hline it & 6 & 2 & 2 & $75 \%$ & $25 \%$ & $25 \%$ & & & \\
\hline street & 6 & 5 & 2 & $75 \%$ & $63 \%$ & $25 \%$ & & & \\
\hline threat & 4 & 3 & 4 & $50 \%$ & $38 \%$ & $50 \%$ & & & \\
\hline
\end{tabular}

According to these results, $42 \%$ of the times the production of final $/ \mathrm{t} / \mathrm{is}$ aligned with the RP model (released /t/), whereas $25 \%(67 \%-42 \%)$ it is produced as an unreleased /t/, and $33 \%$ other alterations could be observed as follows:

a) Substitution by fricatives $/ \mathrm{z} /$ and $/ \theta /$, or by affricate $/ \mathrm{t} 6 /$.

b) Addition of phoneme $/ \mathrm{s} /$ before or after $/ \mathrm{t} /$.

A phonetic transfer from Northern Vietnamese to English is produced in one-fourth of the cases (when unreleased /t/ occurs), one-third of the times final / $t /$ is either substituted by a fricative or affricate consonant, or the phoneme /s/ is added before or after it. In $42 \%$ of the times final /t/ is pronounced according to the RP model, i.e. with the phoneme /t/ released. Although this research is not related to intelligibility, we may consider that the substitution of final / $t$ / by other phonemes may negatively affect it, but this problem may be the topic of another research.

Table 6 includes the pronunciation of the final obstruent / $\mathrm{k} /$ by the eight Vietnamese participants in the target words. Table 7 exhibits the corresponding quantifications of these results, and its columns follow the same criteria as explained for Table 3.

Table 6. Production of final /k/ ('[+]' released or '[-]' unreleased).

\begin{tabular}{|l|c|c|c|c|c|c|c|c|}
\hline \multirow{3}{*}{ Words } & \multicolumn{7}{|c|}{ Participants } \\
\cline { 2 - 9 } & $\mathbf{1}$ & $\mathbf{2}$ & $\mathbf{3}$ & $\mathbf{4}$ & $\mathbf{5}$ & $\mathbf{6}$ & $\mathbf{7}$ & $\mathbf{8}$ \\
\hline park & $/ \mathrm{k} /[+]$ & $/ \mathrm{k} /[+]$ & $/ \mathrm{k} /[+]$ & $/ \mathrm{k} /[+]$ & $/ \mathrm{k} /[-]$ & $/ \mathrm{k} /[-]$ & $/ \mathrm{k} /[-]$ & $/ \mathrm{k} /[+]$ \\
\hline take & $/ \mathrm{k} /[-]$ & $/ \mathrm{k} /[+]$ & $/ \mathrm{k} /[+]$ & $/ \mathrm{k} /[+]$ & $/ \mathrm{k} /[+]$ & $/ \mathrm{k} /[+]$ & $/ \mathrm{k} /[-]$ & $/ \mathrm{k} /[+]$ \\
\hline
\end{tabular}


According to these results, $31 \%(100 \%-69 \%)$ of the times, the pronunciation of final $/ \mathrm{k} /$ is unreleased. This phenomenon is associated with a phonetic transfer from Northern Vietnamese to English because it is in this way how this phoneme is pronounced in Northern Vietnamese. In $69 \%$ of the productions, final $/ \mathrm{k} /$ is pronounced with a released burst; therefore, accommodating its pronunciation phonetically to that of the model RP.

Table 7: Quantification of the production of final /k/ ('[+]' released or '[-]' unreleased).

\begin{tabular}{|l|c|c|c|c|c|c|c|c|c|}
\hline \multirow{2}{*}{ Words } & \multirow{2}{*}{$/ \mathbf{k} /$} & \multirow{2}{*}{$/ \mathbf{k} /[+]$} & \multirow{2}{*}{ other } & \multicolumn{3}{|c|}{$\%$ over words } & \multicolumn{3}{c|}{ \% over FO } \\
\cline { 5 - 8 } & & & & $/ \mathbf{k} /$ & $/ \mathbf{k} /[+]$ & other & $/ \mathrm{k} /$ & $/ \mathbf{k} /[+]$ & other \\
\hline park & 8 & 5 & 0 & $100 \%$ & $63 \%$ & $0 \%$ & \multirow{2}{*}{$100 \%$} & \multirow{2}{*}{$69 \%$} & $0 \%$ \\
\hline take & 8 & 6 & 0 & $100 \%$ & $75 \%$ & $0 \%$ & & & \\
\hline
\end{tabular}

\subsection{Results of the Acoustic Analysis}

\subsubsection{Consonant Clusters}

As stated in Subsection 1.3.1, the absence of consonant clusters is a common feature in all Vietnamese dialects. This fact makes it difficult for Vietnamese speakers to pronounce the numerous consonant clusters in the English phonological system, where there may occur clusters of up to three consonants in word onset position and up to four consonants in word coda position.

According to the results obtained from the auditory analysis, the cluster represented orthographically by the group $t r$, whose RP pronunciation is /tr/, has been produced in some cases with the affricate $/ \mathrm{t} 6 /$. Sometimes the presence or absence of friction is difficult to distinguish. In the case of /tr/, the phoneme /r/ is devoiced, so when observing this cluster, slight friction appears, and it is not possible to differentiate it from /tc/. The only factor that may help is the transition of the formants of the approximant /r/ to the vowel since $\mathrm{F} 2$ and $\mathrm{F} 3$ rise from the production of $/ \mathrm{r} /$ to the following vowel; this rise is more visible for F2. Figure 1 is an example of this effect; it shows the formant structure of the word trip pronounced by the English participant 9. The rise of F2 and F3 (mainly F2) can be observed from their initial to their final positions, in which they correspond to the vowel / $/$ /.

Figure 2 shows the graphs of the same word, trip, pronounced by the Vietnamese participants 3 and 4 .

We can observe that F2 and F3 in participant 3 rise from the beginning to the end of the phoneme $/ \mathrm{r} /$; this fact supports the presence of the approximant $/ \mathrm{r} /$. The observed production of the group $t r$ in participant 3 is the cluster/tr/. However, F2 and F3 are steady or even fall in the production of participant 4, supporting the idea of an absence of the approximant $/ \mathrm{r} /$ before the vowel. The observed production of the group $t r$ in participant 4 is the affricate $/ \mathrm{t} 6 /$. 
Figure 1. Waveform, spectrographic representation and formant structure of the word trip pronounced by participant 9 .

$$
\text { trip_9-RP }
$$
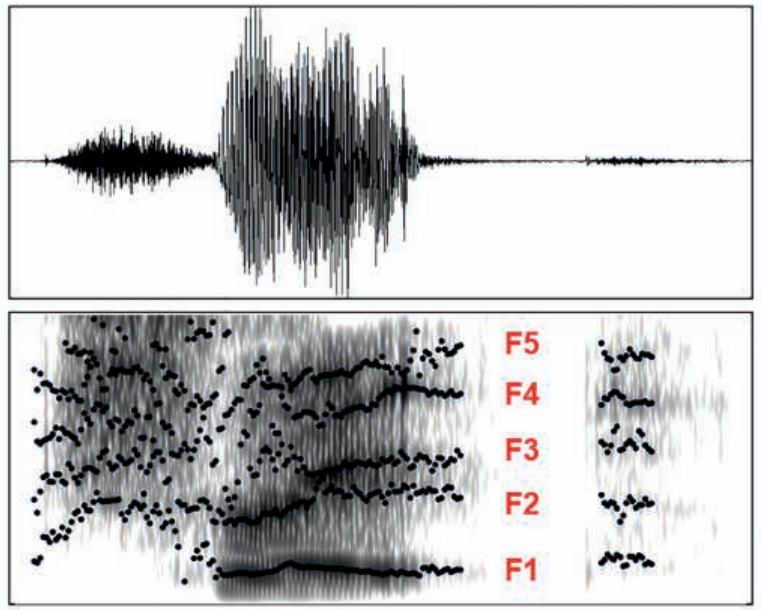

Figure 2. Waveform, spectrographic representation and formant structure of the word trip pronounced by participants 3 and 4 .
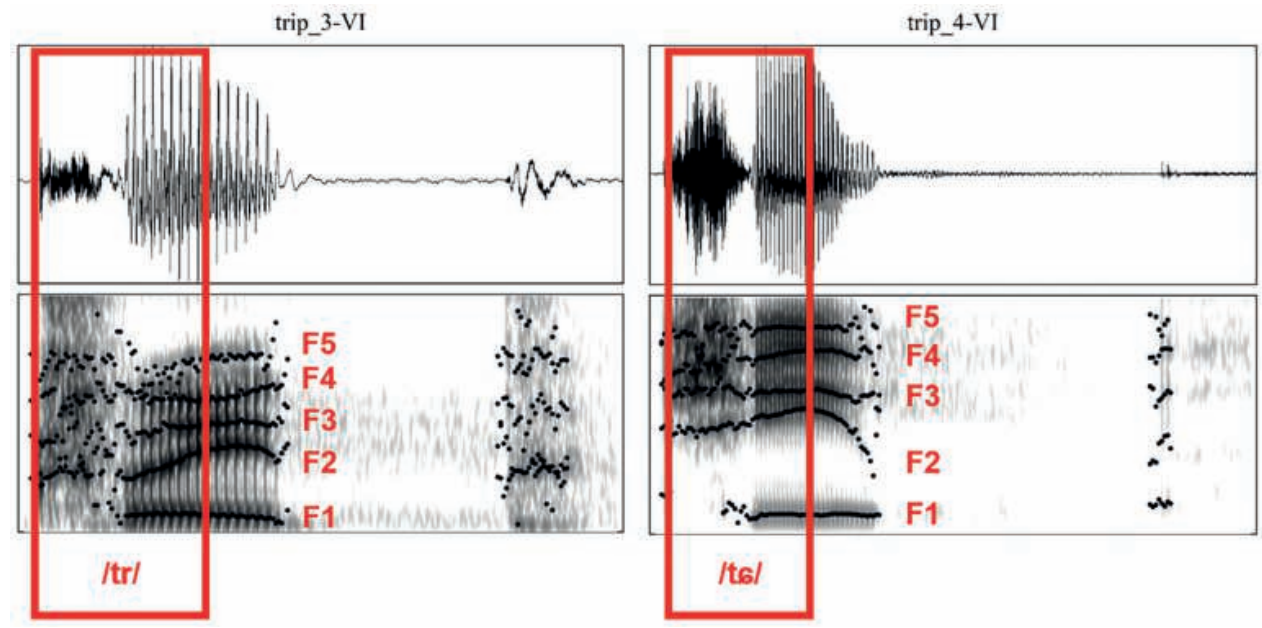

Another example of the same consonant cluster is shown in Figure 3, which represents a comparison between the productions of the Vietnamese participants 1 and 4 of the word street. 
The formants F2 and F3 in the acoustic analysis of participant 1 keep steady, which supports the auditory perception of the affricate /t $6 /$. In contrast, the rise in those formants shown in the acoustic analysis of participant 4 indicates the presence of the approximant $/ \mathrm{r} /$ between the plosive / $\mathrm{t} /$ and the following vowel.

Figure 3. Waveform, spectrographic representation and formant structure of the word street pronounced by participants 1 and 4 .
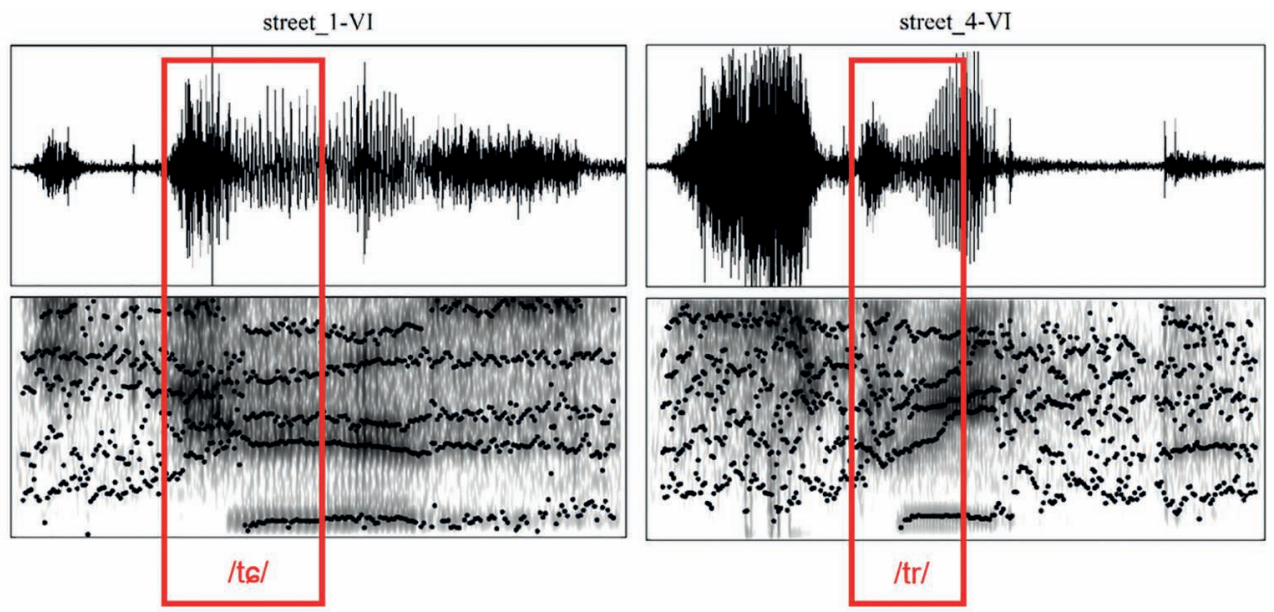

\subsubsection{Voiceless Final Obstruents}

In Section 1.3.2, we saw that one crucial difference between Vietnamese and English regarding the voiceless final obstruents $(/ \mathrm{p} /, / \mathrm{t} /$ and $/ \mathrm{k} /)$ is that these phonemes are unreleased in all varieties of Vietnamese, but they can be released in English. According to Raphael, Borden and Harris (2011: 131), two features characterise stop production: a 'silent gap' during which there is no flow of air out of the vocal tract, and a noise burst at the moment of release. These features may be well observed in the acoustic analysis of the corresponding audio files. Figures 4, 5 and 6 show the waveforms, spectrograms and formant structures of the words creep, coat and take respectively, pronounced by the two English participants (numbers 9 and 10) used as a model.

When we observe the production of the voiceless final obstruents by the eight Vietnamese participants, we can detect the following two phenomena, which are shown in Tables 2, 4 and 6:

1) Some participants substituted the final obstruent by other phonemes (mainly affricate and fricative) or omitted that final consonant. This effect is mainly observed with the phoneme $/ \mathrm{t} /$. 
2) When the participants kept the correct final phoneme (according to RP pronunciation), some of them produced them with an absence of release.

Figure 4. Waveform, spectrographic representation and formant structure of the word creep pronounced by participants 9 and 10 .

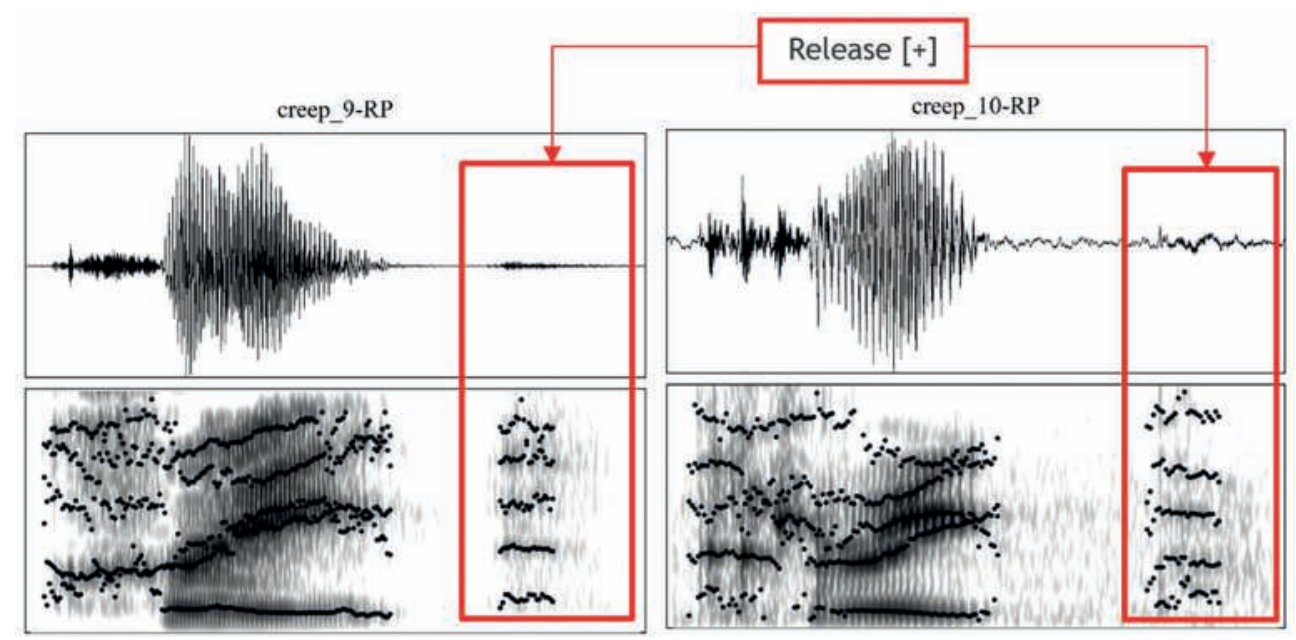

Figures 7, 8 and 9 show some examples of the absence of release in the production of words ending in $/ \mathrm{p} /, / \mathrm{t} /$ and $/ \mathrm{k} /$ respectively, whereas Figure 10 shows the graphs of the words street and threat, where the final obstruent was produced with the fricatives $/ \theta /$ and /z/ respectively. 'The aperiodic source that marks fricatives is created in the vocal tract by sending the breath stream (either phonated or unphonated) through constrictions formed in the tract' (RAPHAEL, BORDEN and HARRIS, 2011: 124). The presence of a fricative is observed in the spectrogram by a prolonged aperiodic sound with little or no formant structure because they are nonresonant consonants. 
Figure 5. Waveform, spectrographic representation and formant structure of the word coat pronounced by participants 9 and 10 .

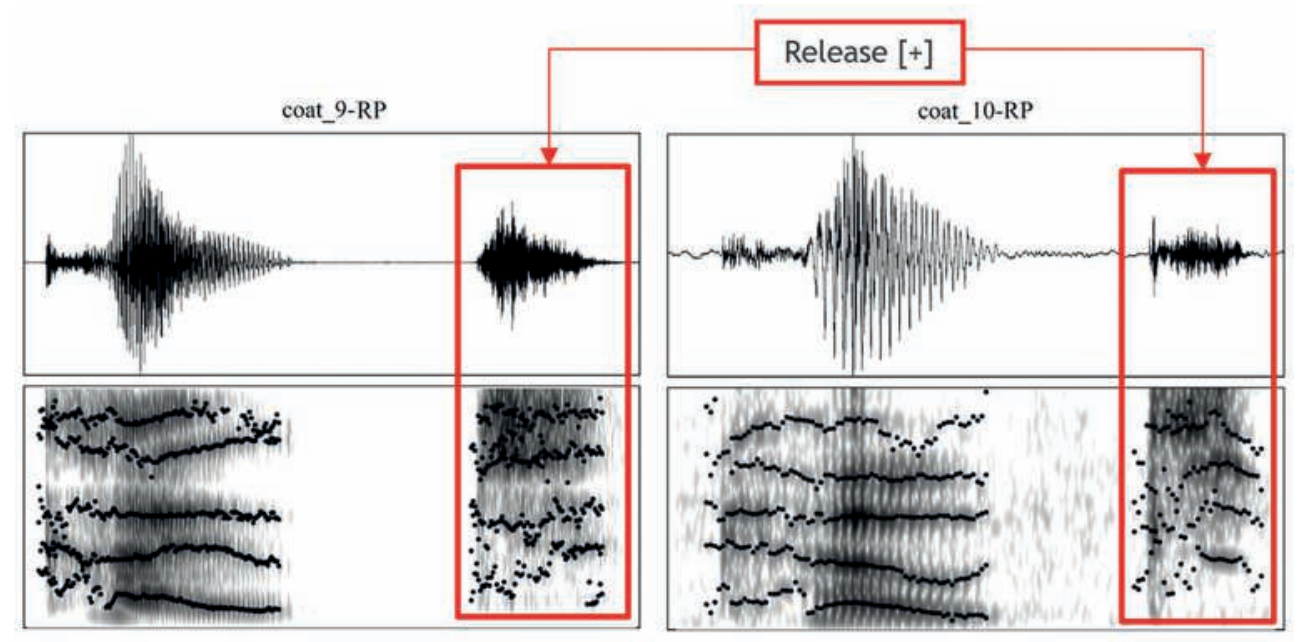

Figure 6. Waveform, spectrographic representation and formant structure of the word take pronounced by participants 9 and 10 .

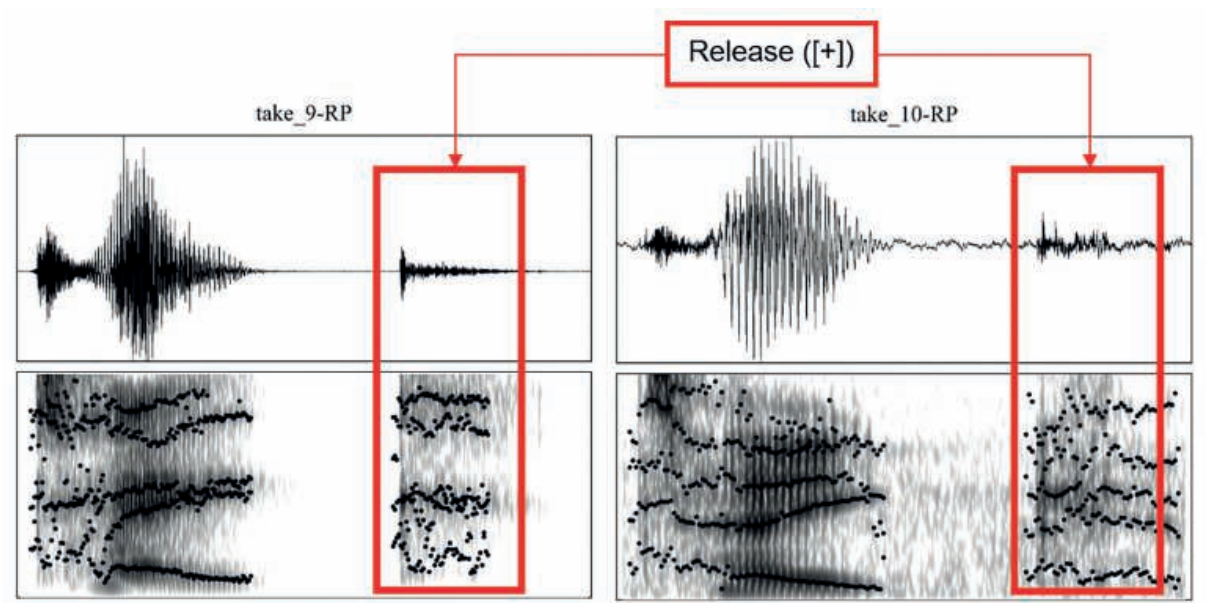


Figure 7. Waveform and spectrogram representation and formant structure of the word top pronounced by participants 1 and 4 .

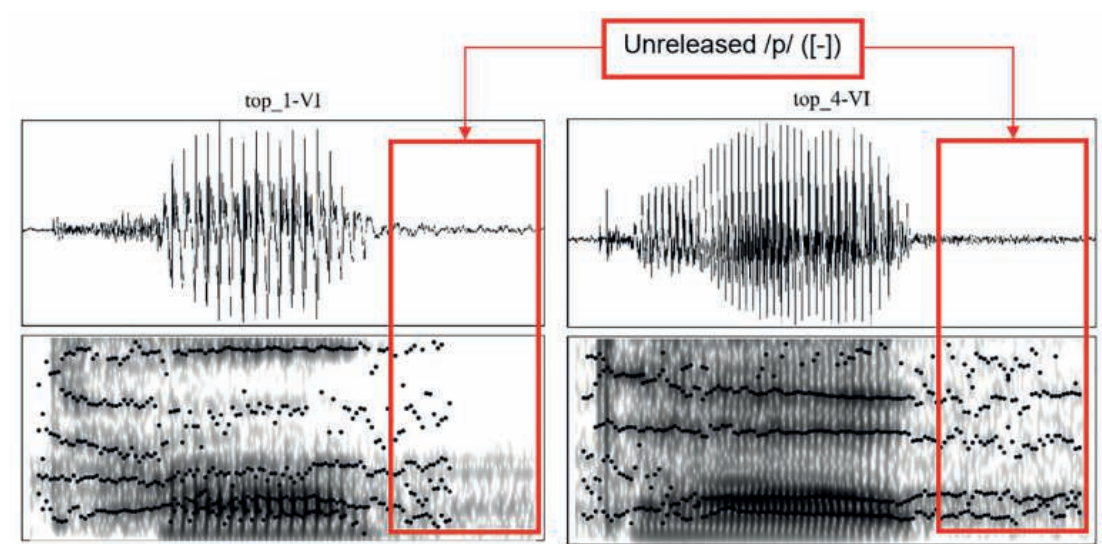

Figure 8. Waveform, spectrographic representation and formant structure of the word coat pronounced by participant 6 and street by participant 3 .

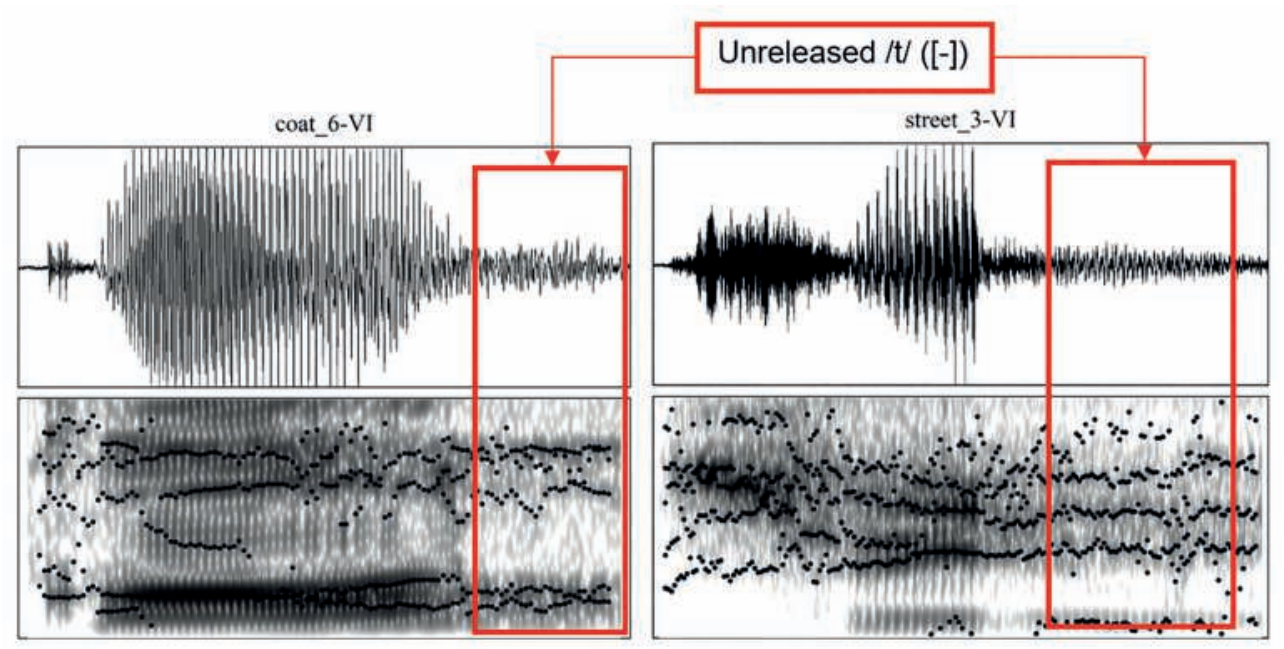


Figure 9. Waveform, spectrographic representation and formant structure of the word park pronounced by participants 5 and 6 .

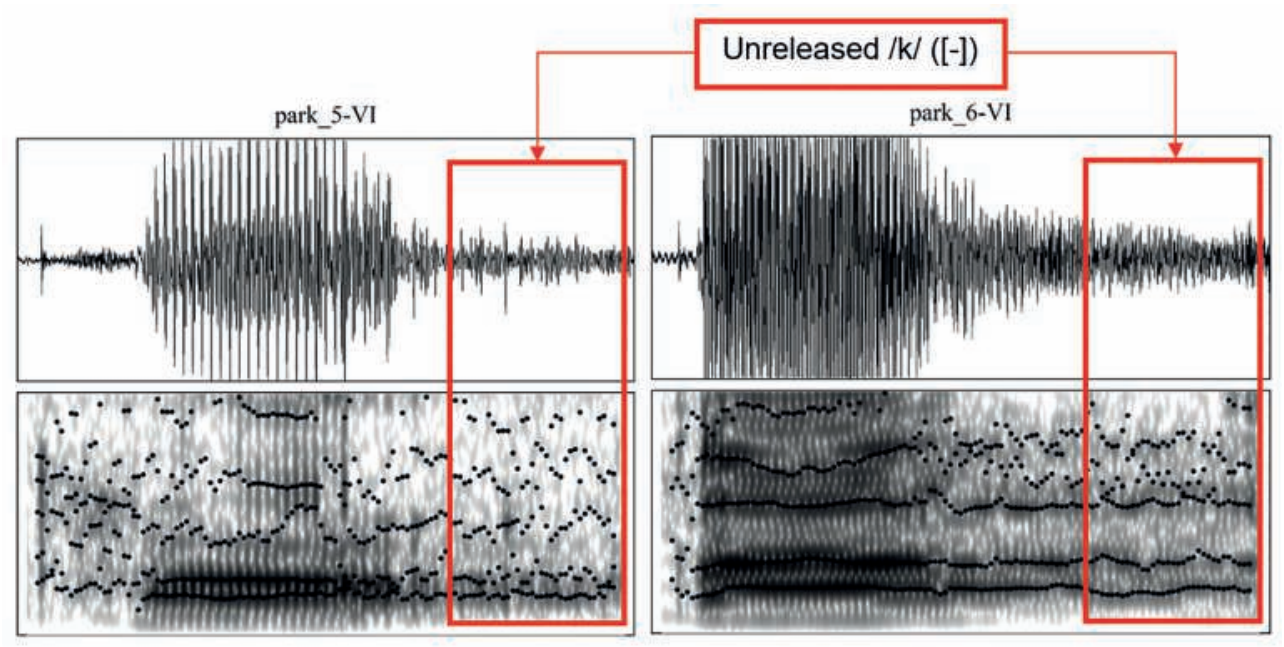

Figure 10. Waveform, spectrographic representation and formant structure of the words street and threat pronounced by participant 7 .

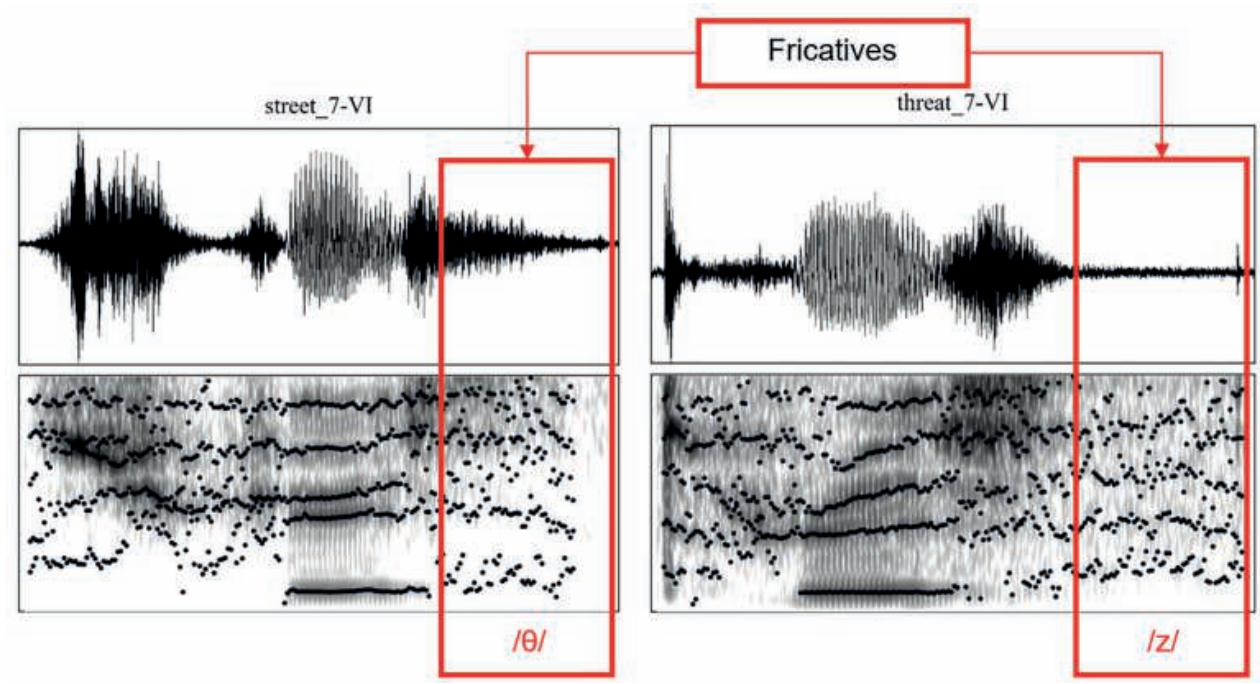




\section{DISCUSSION}

This section interprets the results included in Section 3 and evaluates whether the hypothesis introduced in Section 1 can be verified. The objective of this article was to study some aspects of phonetic and phonological transfer from Northern Vietnamese to English. In this section, we will be able to detect phonetic or phonological transfer features observed in the production of the consonant clusters and the voiced final obstruents by the eight Vietnamese participants.

\subsection{Consonant Clusters}

With respect to onset consonant clusters, there is one cluster of three consonants in onset position in the target words (/str/) and eleven clusters of two consonants (/k1/, /sk/, /sp/, /kr/, /pr/, /br/, /fr/, /tr/, /gr/, / / r/ and /fr/). These clusters are shown in Table 1.

According to the results, the clusters $/ \mathrm{kl} /, / \mathrm{sk} /$ and $/ \mathrm{sp} /$ were pronounced following the RP model. The rest of them, which have the approximant $/ \mathrm{r} /$ as the last consonant, showed some kind of deviations from the model. The forty-five segmental deviations observed in these consonant clusters can be categorised into the following groups:

a) Substitution. There were thirty-six cases of substitution of one consonant by another $(80 \%)$; these cases can be classified as follows:

i) Substitution by a plosive. There were twenty cases of this deviation in the clusters /br/, /fr/, /gr/, /kr/ and / $/ \mathrm{r} /$, all of them ending with the approximant $/ \mathrm{r} /$. The first plosives or fricatives were substituted by the plosives $/ \mathrm{p} /, / \mathrm{t} /, / \mathrm{k} /, / \mathrm{b} /$ or $/ \mathrm{g} /$, and the approximant remains.

ii) Substitution by an affricate. There are eight cases where the cluster /tr/ was substituted by the affricate $/ \mathrm{t} 6 /$.

iii) Substitution of fricatives. This deviation was observed six times only with the cluster / $/ \mathrm{r} /$, where the fricative / $/$ / was substituted by the also fricative /s/.

iv) Substitution of approximants. There are two residual cases where the approximant /r/ was substituted by the also approximant /w/. This phenomenon was observed with the cluster $/ \int \mathrm{r} /$.

b) Consonant deletion. There are four cases of consonant deletion (9\%), three of them in the cluster /str/, where the plosive /t/ was deleted, and one in /pr/ with deletion of the approximant.

c) Addition. Five cases $(11 \%)$ of epenthesis were observed: a schwa (/ə/) was added twice between the two consonants of the cluster /br/, once before the cluster /str/, and once after the cluster $/ \mathrm{fr} /$. The last case of epenthesis is the addition of the plosive / $/$ / between the two consonants of the cluster $/ \mathrm{fr} /$.

As far as medial consonant clusters are concerned, there are two clusters of three consonants (/lpt $/$ and $/ \mathrm{ntl} /)$ and two clusters of two consonants $(/ \mathrm{kJ} /$ and $/ \mathrm{pl} /)$ in medial 
position. The deviations observed are of two kinds: substitutions and deletions. Besides, some consonant clusters were affected by both, as is explained below:

1) Substitution. The most common substitution appeared with the affricate $/ \mathrm{t} f /$ in the cluster /lpt $\int /$ and the plosive /t/ in the cluster /ntl/; those phonemes were substituted by the affricate / $\mathrm{t} / \mathrm{l}$ in five occurrences. Three times, we could observe the substitution of the post-alveolar / $/$ by the alveolar /s/ in the cluster $/ \mathrm{kJ} /$. One residual case is the substitution of the plosive /p/ by the fricative /f/ in the cluster /pl/.

2) Deletion. The plosive $/ \mathrm{k} /$ was deleted three times in the cluster $/ \mathrm{kJ} /$, and the plosive /t/ was deleted in the cluster /ntl/ four times. In eight occurrences, the cluster /lpt $\mathrm{f} /$ suffered deletion of one or two consonants.

3) Merging of deviations. The case of the cluster /lpt $\int /$ deserves a separate group because, apart from the substitution by the affricate / $\mathrm{t} 6 /$ and the deletions mentioned above, the productions by all participants had some kind of deviation: deletions, substitutions or a combination of both.

Finally, there are seven consonant clusters in coda position, five of two consonants (/dz/, $/ \mathrm{kt} /, / \mathrm{nt} /, / \mathrm{st} /$ and $/ \mathrm{nk} /$ ), one of three consonants (/kst/) and one of four consonants (/ksts/). The productions of all consonant clusters had some kind of deviations, thirty-nine in our observation, which can be grouped as follows:

a) Substitution. There were five cases of substitution. These substitutions were varied: /kt/ was substituted by /x/, /nt/ by /st/, and /st/ by /k/ or /tc/.

b) Deletion. This was a common deviation with thirty-four cases observed, most of them in the clusters $/ \mathrm{dz} /, / \mathrm{kt} /, / \mathrm{nt} /$, /st/ and $/ \mathrm{yk} /$. The clusters $/ \mathrm{kst} /$ and, especially, $/ \mathrm{ksts} /$ led to deletions of different consonants in each case. The last cluster was never pronounced with all its consonants, according to the RP model.

The results presented so far with respect to consonant clusters show that it is possible to group the deviations from RP model into three main categories: substitution, consonant deletion and addition. The deviations observed in all positions are the following:

a) Substitution. Table 8 represents the substitutions observed in consonant clusters in onset, medial and coda positions according to the explanations given in the corresponding previous subsections. For each position in the word (onset, medial and coda), this table shows the phonemic transcription according to the RP model of some phonemes of the consonant clusters in the target words ('Source' column), the transcriptions of the productions by the Vietnamese participants ('Target' column), and the number of substitutions observed. The arrows represent the direction of the substitutions. 
Table 8: Substitutions observed in consonant clusters.

\begin{tabular}{|c|c|c|c|c|c|c|c|c|}
\hline \multicolumn{3}{|c|}{ Onset } & \multicolumn{3}{|c|}{ Medial } & \multicolumn{3}{|c|}{ Coda } \\
\hline Source & Target & No. & Source & Target & No. & Source & Target & No. \\
\hline \multirow{5}{*}{ /frr/ } & $\nabla^{/ p r /}$ & 3 & $\mid t \mathrm{t} / \mathrm{Y}$ & & & $/ \mathrm{kt} /$ & $\rightarrow|x|$ & 1 \\
\hline & $\mid t r l$ & 8 & $\operatorname{lnt} /$ & & & /nt/ & $\rightarrow$ /st/ & 1 \\
\hline & $/ \mathrm{kr} /$ & 1 & $/ \mathrm{k} J /-$ & $\rightarrow / \mathrm{s} /$ & 3 & \multirow{2}{*}{ /st/ } & $\rightarrow / k /$ & 2 \\
\hline & /br/ & 7 & $/ \mathrm{pl} /-$ & $\rightarrow / f \mathrm{fl}$ & 1 & & $\Delta / t_{6} /$ & 1 \\
\hline & $/ \mathrm{gr} /$ & 1 & & & & & & \\
\hline \multirow[t]{4}{*}{$\mid \mathrm{tr} /-$} & $\rightarrow\left|t_{6}\right|$ & 8 & & & & & & \\
\hline & $\pi^{1 \mathrm{~s}-1}$ & 5 & & & & & & \\
\hline & $\rightarrow|s w|$ & $2\left({ }^{*}\right)$ & & & & & & \\
\hline & $\bar{\Delta}_{/ \mathrm{Jw} /}$ & 1 & & & & & & \\
\hline \multicolumn{3}{|c|}{ Onset substitutions: 36} & \multicolumn{3}{|c|}{ Medial substitutions: 9} & \multicolumn{3}{|c|}{ Coda substitutions: 5} \\
\hline \multicolumn{9}{|c|}{ Total substitutions: 50} \\
\hline
\end{tabular}

$\left.{ }^{*}\right)$ Only one case but two substitutions: $/ \mathrm{J} / \longrightarrow / \mathrm{s} /$ and $/ \mathrm{r} / \longrightarrow / \mathrm{w} /$

The most crucial substitution was where the target phoneme is the affricate $/ t_{6} /$; it appears fourteen times in all positions (28\% over the total number of substitutions). The observation of this phoneme in the productions of the Vietnamese participants corroborates the statement of Kirby (2011) explained in Subsection 1.3.1. According to this author, the groups of consonants $c h$ and $t r$ are pronounced in Northern Vietnamese as the palatal affricate $/ \mathrm{t} c /$. This fact and the absence in Northern Vietnamese of consonant clusters explain why this substitution is a clear case of phonological transfer from Northern Vietnamese to English. Northern Vietnamese speakers tend to pronounce the English cluster represented by $t r$ as this group is pronounced in their language.

Another phenomenon observed in Table 8 is the substitutions of the first consonant in the onset clusters /br/, /fr/, /gr/, /kr/ and / $\theta \mathrm{r} /$ by the plosives /p/, /t/, /k/, /b/ or /g/, apparently at random, without fixed rules. These substitutions appeared twenty times in this research, and they might be explained as caused by a hypercorrection effect over the participants. In the absence of consonant clusters in Vietnamese, the participants make an effort to maintain the consonant cluster but substitute in some cases the first consonant by another one. 
One last remarkable substitution is that of the post-alveolar $/ \delta /$ by the alveolar $/ \mathrm{s} / \mathrm{in}$ nine cases. This phenomenon is also a phonological transfer since the phoneme $/ \int /$ does not exist in Northern Vietnamese, and sometimes it is substituted by the also voiceless fricative /s/, which exists in this language. The other seven substitutions observed can be considered residual and accidental and do not deserve more analysis.

b) Deletion. There are no systematic rules regarding the fifty-three cases of deletion observed. Northern Vietnamese has no consonant clusters, and the deletions are used to simplify them. The deletions observed can be considered cases of phonological transfer to accommodate the structure of the syllables to that of Northern Vietnamese.

The more consonants the cluster has, the more consonants are deleted; this effect is observed in the clusters $/ \mathrm{lpt} \mathrm{J} / \mathrm{kst} / \mathrm{and} / \mathrm{ksts} /$, where there were cases of deletion of any consonant. However, it is remarkable that when the coda clusters $/ \mathrm{nt} /$ and $/ \mathrm{yk} /$ suffer deletion (nine times), the nasal consonant remains; this is an influence of the Northern Vietnamese phonology since those nasals belong to its repertoire.

c) Addition. Five cases of addition were observed, and they occur only in onset position; they are epenthesis of shwa (/a/) in four cases and of /t/ in one case. This phenomenon is a case of phonological transfer from Northern Vietnamese to English because it is a mechanism to adapt the structure of the English syllables with consonant clusters to the structure of the Northern Vietnamese syllable.

Northern Vietnamese phonological system lacks consonant clusters, so, according to the above explanations, L1 speakers tend to adequate their production of L2 to their phonological system.

Consonant clusters is a case where, in words of Jenkins (2000: 33), 'sounds that are phonetically very different from those in the L1 are initially likely to prove most difficult to produce since the articulators must be activated in new ways'. Therefore, the results of this research confirm and illustrate the first aspect of the hypothesis: the differences of both phonological systems trigger a phonological transfer from L1 to L2.

\subsection{Comparative Study of Voiceless Final Obstruents}

Table 9 summarises the characteristics of the productions of the three voiceless final obstruents, which were included in Section 3. This table shows the percentage of occurrence observed for each characteristic: pronunciation according to RP model ('/RP/ [+]'), pronunciation with the RP phoneme but unreleased ('/RP/ [-]'), and pronunciation of other phonemes in its place. 
Table 9: Production of voiceless final obstruents.

\begin{tabular}{|c|c|c|c|}
\hline Final obstruent & /RP/ [+] & /RP/ [-] & other phonemes \\
\hline$/ \mathrm{p} /$ & $77 \%$ & $23 \%$ & $0 \%$ \\
\hline$/ \mathrm{t} /$ & $42 \%$ & $25 \%$ & $33 \%$ \\
\hline$/ \mathrm{k} /$ & $69 \%$ & $31 \%$ & $0 \%$ \\
\hline
\end{tabular}

The highest level of accommodation with the RP model (/RP/ [+]) is achieved by final $/ \mathrm{p} /$, and the lowest by final $/ \mathrm{t} /$, which is the only phoneme in which we have observed substitutions by other phonemes: fricatives $/ \mathrm{z} /$ and $/ \theta /$, and affricate $/ \mathrm{t} 6 /$. We can consider these substitutions of phonemes as a phonological transfer from L1 to L2. On the other hand, the column headed by '/RP/ [-]' represents the rating of phonetic transfer from Northern Vietnamese to English for each final obstruent because it indicates how often Northern Vietnamese speakers produced the L2 voiceless final obstruents similarly to those consonants in L1. Final /k/ has the highest level of transfer.

Voiceless final obstruents are cases where 'there is any degree of similarity between L1 and L2 sounds', as Section 1.2 explains based on the statement of Jenkins (2000: 33). These results confirm the second aspect of the hypothesis: the similarities of both phonological or phonetic systems activate a phonological or phonetic transfer from L1 to L2. Furthermore, this research corroborates the unreleased character of the Vietnamese final obstruents observed by Tang (2007: 6), as explained in Subsection 1.3.2.

What seems evident from the study of voiceless final obstruents is that the phoneme /t/ in final position results to be the most problematic for the production by Northern Vietnamese speakers. It has a low level of accommodation to the RP model, and it is the phoneme in which we observe substitutions by other phonemes, what might lead to problems of intelligibility.

\section{CONCLUSIONS}

This article has analysed how phonetic and phonological transfer can be observed in the production of English consonant clusters and voiceless final obstruents by eight Northern Vietnamese speakers. The hypothesis was that two opposite phenomena (similarities and differences in the phonetic and phonological systems of L1 and L2) could lead to a transfer from the former to the latter.

The deviations in the production of consonant clusters have been classified into three categories: substitutions, consonant deletions and additions. We have found phonological transfer in each one of those groups. One frequent phonological transfer is the substitution of the English cluster/tr/ by the Northern Vietnamese affricate /t6/. This transfer has its explanation in the fact that the consonantal group $t r$ is pronounced in Northern Vietnamese as /t6/. This phoneme also appeared as the target phoneme of other consonant clusters in medial and coda positions. There have also been substitutions of the phoneme $/ \mathrm{J} /$, inexistent 
in Vietnamese, by the alveolar /s/. The cases of deletion and addition were caused by an adaptation of the English syllabic structure to that of Northern Vietnamese. The fact that Vietnamese lacks consonant clusters may lead to a reduction in the number of consonants observed or the addition of other phonemes through epenthesis.

Regarding voiceless final obstruents, the results show an average phonetic transfer of $26 \%(23 \%$ for $/ \mathrm{p} /, 25 \%$ for $/ \mathrm{t} /$ and $31 \%$ for $/ \mathrm{k} /)$. Thus, $/ \mathrm{k} /$ is the final obstruent with more transfer rate; however, the differences are not substantial. What is important to mention here is that in $33 \%$ of the cases, the final /t/ suffered deviations, such as substitutions by a fricative or affricate $(/ \mathrm{z} /, / \theta /, / \mathrm{t} 6 /)$, or addition of the phoneme $/ \mathrm{s} /$. This phenomenon is important to be taken into account in terms of intelligibility.

In summary, defining phonological and phonetic transfer as the influence of L1 phonology or phonetics on L2 pronunciation, we can conclude that the existence of either different or similar features between the two phonological or phonetic systems - consonant clusters and voiceless final obstruents, respectively - triggers those transfers, corroborating in this way the hypothesis of this research. In both cases, L1 speakers tend to adapt their production of L2 features according to the phonological or phonetic system of L1. We have observed a tendency to pronounce the group $t r$ with the phoneme $/ \mathrm{t} 6 /$, the substitution of $/ \mathrm{f} /$ by /s/, or epenthesis in some cases to adapt the L2 syllabic system to that of L1. Regarding voiceless final obstruents, although phonemically they are similar in both languages, there is a tendency to pronounce them with an unreleased mechanism by L1 speakers, leading to phonetic transfer. There were also some cases of substitution of the final obstruent /t/ by the affricate $/ \mathrm{t} 6 /$; as explained above, this phoneme has a significant influence on the production of L1 speakers.

Additionally, we observed cases of hypercorrection in some consonant clusters of two consonants ending in $/ \mathrm{r} /$; the participants kept this phoneme but changed the first one, perhaps in an effort to get correctness. In any case, the differences in both phonological systems cause some kind of deviations.

This article has not analysed the effect of the observed phonetic or phonological transfers on intelligibility, which might be the object of further research. Likewise, the idea of correctness has been out of this investigation. However, the conclusions of this study have an impact on the following fields: 1) the study of Northern Vietnamese English as another variety of English, with its particular characteristics, as explained above; 2) the intelligibility levels of speakers of other linguistic backgrounds when speaking English with Northern Vietnamese natives in international contexts; and 3) the English teaching methodology to Northern Vietnamese students, making them focus on aspects that they should improve if they want to accommodate their production to that of the RP model.

This research contributes to filling the existing gap in the studies of the phonetic and phonological transfer from Northern Vietnamese to English in an international environment. However, further investigations will be needed both in the segmental and suprasegmental levels to get ample knowledge of these phenomena. 


\section{REFERENCES}

Alves, Mark J. (2009): "Loanwords in Vietnamese". Loanwords in the World's Language: A Comparative Handbook, January, ed. Martin Haspelmath and Uri Tadmorpp, Berlin, De Gruyter Mouton, pp. 617-637. https://doi.org/10.1515/9783110218442

Austen, Jane (2007): Pride and Prejudice, in Jane Austen, Seven Novels, New York, Barnes \& Noble, pp. 199-405.

Boersma, Paul, and David Weenink (2005): Praat: doing phonetics by computer, accesed 27-112020, http://www.praat.org

Cheng, Li-Rong L. (1987): Assessing Asian language performance: Guidelines for evaluating limited-English-proficient students, Rockville, MD, Aspen Publishers.

De Rhodes, Alexandre (1651): Dictionarium Annnamiticum [sic] Lusitanum, et Latinum, Rome, Sacrae Congregationis de Propaganda Fide.

HarRis, Jimmy G. (2006): "A Palatographic study of places of articulation in Thai and some other Southeast Asian languages: Dentals, alveolars, and palatals", Readings in articulatory phonetics 1: Consonants and phonation types, ed. James E. Harris, Bangkok, Ek Phim Thai Co, pp. 63-91.

Jenkins, JenNifer. (2000): The phonology of English as an international language, Oxford, Oxford University Press.

Kirby, JAMES K. (2011): Vietnamese (Hanoi Vietnamese): Journal of the International Phonetic Association, 41.3, pp. 381-392. https://doi.org/10.1017/S0025100311000181

NGuYễN, Đin-HoÀ (1997): Vietnamese: Tiếng Việt không son phấn, Vol. 9, Amsterdam/Philadelphia, John Benjamins.

Raphael, Lawrence J., Gloria J. Borden, and Katherine S. Harris (2011): Speech Science Primer. Phycology, Accoustics, and Perception of Speech, Philadelphia, Lippincott Williams \& Wilkins.

SMith, LARRy E. (1976): "English as an International Auxiliary Language” RELC Journal, 7.2, pp. 38-42. https://doi.org/10.1515/jelf-2015-0001

TANG, GIANG (2007): "Cross-linguistic analysis of Vietnamese and English with implications for Vietnamese language acquisition and maintenance in the United States", Journal of Southeast Asian American Education and Advancement, 2.1, pp. 1-31. https://doi.org/10.7771/2153-8999.1085 